\title{
Quantitative ultrasound assessment of bone in preterm and term neonates
}

\author{
H McDevitt, C Tomlinson, M P White, S F Ahmed
}

Arch Dis Child Fetal Neonatal Ed 2005;90:F341-F342. doi: 10.1136/adc.2004.065276

There is a need to explore novel methods of assessing bone health in sick preterm infants. This study of the speed of sound in the long bones of newborn term and preterm infants shows that, in this population, this technique is not site specific and has a high degree of interobserver and intraobserver precision. The speed of sound in newborn infants is primarily dependent on gestation rather than birth weight.

$\mathrm{P}$ oor bone health in preterm infants is due to a combination of reduced mineralisation and low bone mass, and its assessment remains difficult. ${ }^{1}$ Preliminary studies suggest that the measurement of speed of sound (SOS) by quantitative ultrasound may be a useful adjunct for assessing bone health in infants. ${ }^{2}{ }^{3}$ However, its methodology needs further exploration, especially if it is used in the sick, preterm infant. This study was performed to assess the reliability of the technique in this setting and to assess the relation of SOS to the gestation and size of the infant.

\section{PATIENTS AND METHODS}

SOS was measured at a median age of 3 days (interquartile range 2-5) in 110 (60 male) infants with a median gestational age of 36 weeks (range 24-41) and median birth weight of 2565 g (680-4600) (table 1). The cohort, which included five sets of twins (four of the same sex) was arbitrarily divided into three groups by gestation at birth: A (>37 weeks), B (32-36 weeks), and C ( $<32$ weeks).

SOS was measured using the Sunlight Omnisense 7000P (Sunlight Medical, Tel Aviv, Israel) at the distal third of the radius and the mid shaft of the tibia. The results were expressed in $\mathrm{m} / \mathrm{s}^{4}$ Validation studies were performed to assess: (a) intraobserver variation (multiple measurements performed at one site by the same observer in 15 infants); (b) interobserver variation (repeat measurements on two sites in six infants); (c) variation between different sites in same infant (duplicate scans at each tibia and radius in 20 infants).

XL STAT version 7.0 (Addinsoft, Paris, France) and Microsoft Excel 2000 (Microsoft Corp, Seattle, Washington, USA) were used to determine the precision of the measurements by calculating the coefficient of variation. Differences between groups were compared using the Mann-Whitney U test. Analysis of covariance was performed to assess any associations between variables.

The study was approved by the local ethics committee, and informed consent was obtained from all parents.

\section{RESULTS}

\section{Intraobserver and interobserver variation}

The intraobserver technical error of three repeat measurements at the tibia in 25 infants with a median gestational age of 37 weeks (range 33-41), as assessed by two methods, mean coefficient of variation and root mean square average,
Table 1 Clinical details of study cohort divided into three groups according to gestation

\begin{tabular}{|c|c|c|c|}
\hline & Group A & Group B & Group C \\
\hline Number of infants & 62 & 28 & 20 \\
\hline $\begin{array}{l}\text { Median gestation } \\
\text { (weeks) }\end{array}$ & $40(38,41)$ & $33(32,34)$ & $28(26,30)$ \\
\hline Male:female & $37: 25$ & $14: 14$ & 9:11 \\
\hline $\begin{array}{l}\text { Median birth weight } \\
\text { (g) }\end{array}$ & $\begin{array}{l}3490(3075, \\
3788)\end{array}$ & $\begin{array}{l}1890 \text { (1590, } \\
2310)\end{array}$ & $\begin{array}{l}1080(920, \\
1280)\end{array}$ \\
\hline SGA & 4 & 9 & 2 \\
\hline AGA & 49 & 17 & 17 \\
\hline LGA & 9 & 2 & 1 \\
\hline White & 57 & 28 & 18 \\
\hline Asian & 4 & 0 & 1 \\
\hline Mixed race & 1 & 0 & 1 \\
\hline History of PROM & 1 & 1 & 1 \\
\hline Antenatal steroids & 0 & 10 & 8 \\
\hline Twins & 0 & 9 & 1 \\
\hline Oligohydramnios & 1 & 3 & 0 \\
\hline SVD & 34 & 10 & 10 \\
\hline Caesarean section & 16 & 13 & 8 \\
\hline Forceps & 11 & 3 & 1 \\
\hline Vaginal breech & 1 & 2 & 1 \\
\hline Breast & 27 & 8 & 1 \\
\hline Formula & 23 & 8 & 1 \\
\hline Breast and formula & 12 & 9 & 3 \\
\hline TPN ( \pm enteral feeds) & 0 & 11 & 19 \\
\hline
\end{tabular}

Values in parentheses are 25 th, 75 th centiles.

Group A, born at $>37$ weeks; group B, born at 32-36 weeks; group C, born at $<32$ weeks; SGA, small for gestational age, on or below the 9th centile for weight; AGA, appropriate size for gestational age, between 10th and 90th centile for weight; LGA, large for gestational age, above 90th centile for weight; PROM, prolonged rupture of membranes; SVD, spontaneous vertex delivery; TPN, total parenteral nutrition.

was similarly low at $1.2 \%$ (1SD, $0.8 \%$ ) and $1.4 \%$ respectively. The mean interobserver coefficient of variation for measurements performed by two observers at the tibia in six infants with a median gestational age of 26 weeks (range 24-32) was $1.2 \%(0.7 \%)$.

\section{Intersite variation}

In 20 infants with a median gestational of 37 weeks (range 26-41), measurements were performed at both tibiae and radii. The mean coefficient of variation (ISD) for measurements at all four sites was $2.4 \%(1.2 \%)$, left and right radius was $2.1 \%(1.4 \%)$, right radius and right tibia was $2.3 \%$ $(1.8 \%)$, left radius and left tibia was $1.8 \%(1.2 \%)$, and left tibia and right tibia was $1.7 \%(1.8 \%$.)

\section{Gestation and birth weight}

Median tibial SOS was $3079 \mathrm{~m} / \mathrm{s}$ (interquartile range 30103142 ) in group A. This was significantly higher than in group B who had a median SOS of $2994 \mathrm{~m} / \mathrm{s}$ (interquartile range

Abbreviations: SGA, small for gestational age; SOS, speed of sound; AGA, appropriate size for gestational age 

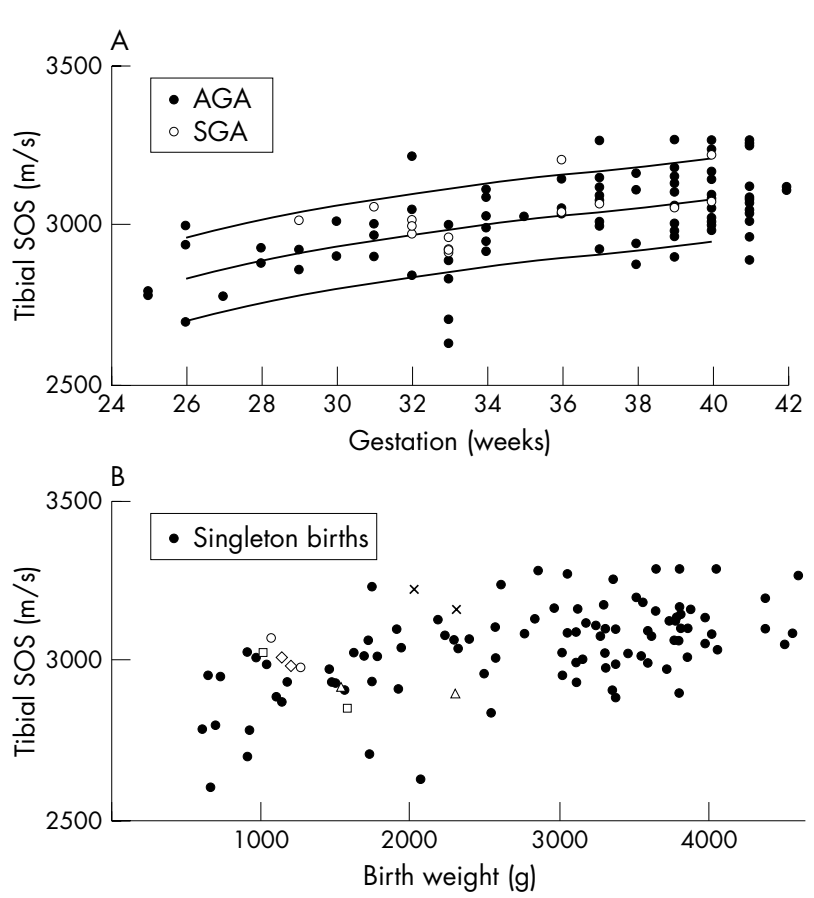

Figure 1 Relation between tibial speed of sound (SOS) and gestation (A) or birth weight (B). (A) AGA, appropriate size for gestational age; SGA, small for gestational age. The dotted lines represent the manufacturer's reference range: mean \pm 1SD. (B) The shapes other than circles represent tibial SOS values for twin pairs of whom one was SGA and one was AGA. In all cases, the twin with the lower birth weight had the higher SOS $(\mathrm{m} / \mathrm{s})$.

2917-3043) or group C with a median SOS of $2911 \mathrm{~m} / \mathrm{s}$ (interquartile range 2816-2982) $(\mathrm{p}<0.001)$ (fig lA). There was no significant correlation between the birth weight and SOS in the infants in group A (fig 1B). Analysis of covariance revealed that $40 \%$ of the variability of tibial SOS was explained by gestation, birth weight, and $\operatorname{sex}(p<0.001)$, and gestation had the greatest impact, followed by birth weight, and then sex.

\section{Influence of size}

In group $\mathrm{A}$ and $\mathrm{B}$, there were no significant differences between the tibial SOS for the small for gestational age (SGA) and appropriate size for gestational age (AGA) infants. However, in group C, median tibial SOS was greater in the two SGA than the AGA infants with a median SOS of $3034 \mathrm{~m} / \mathrm{s}$ (interquartile range 3011-3056) and $2909 \mathrm{~m} / \mathrm{s}$ (interquartile range $2790-2997)$ respectively $(p<0.05)$. In the five sets of twins, tibial SOS tended to be higher in the lighter twin (fig 1B). There were no significant differences between the large for gestational age and AGA infants.

\section{DISCUSSION}

Not only does this study reinforce the finding of previous studies that quantitative ultrasound assessment of SOS can be performed successfully and precisely in infants from 24 weeks gestation through to term, it also shows that, at this age, the assessment is not site specific, and measurements at one tibial site are sufficiently representative of the SOS at the other sites in the neonate. Unlike most previous studies, the infants in this study were measured very shortly after birth, eliminating the confounding effect of the associated comorbidities that are often encountered in the preterm infant. $^{23}$ The close correlation of tibial SOS with gestational age rather than birth weight agrees with other recent reports in which measurements were performed within the first 4 days, suggesting that maturity may be a more important factor in bone health than birth weight. ${ }^{46}$ The relative lack of an association between birth weight and SOS was reinforced, firstly, by the findings in the SGA infants who did not have a lower tibial SOS than gestation matched AGA infants, and secondly by the twin studies in which the tibial SOS was similar, and even slightly higher in the growth retarded twin.

The future application of quantitative ultrasound in assessing the bone health of infants deserves further exploration and the data in this report should prove beneficial in designing longitudinal studies.

\section{ACKNOWLEDGEMENTS}

We are grateful to the parents and babies for participating and to the generous support and encouragement of the Yorkhill Children's Foundation, the St Charles' Place Foundation, and the clinical staff at the three neonatal units.

\section{Authors' affiliations}

H McDevitt, M P White, Neonatal Unit, Southern General Hospital, Glasgow, Scotland, UK

C Tomlinson, Neonatal Unit, Princess Royal Maternity Hospital, Glasgow S F Ahmed, Bone and Endocrine Research Group, Royal Hospital For Sick Children, Yorkhill, Glasgow

Competing interests: none declared

Correspondence to: Dr Ahmed, Bone and Endocrine Research Group, Royal Hospital For Sick Children, Yorkhill, Glasgow, G3 8SJ, Scotland, UK; gcl328@clinmed.gla.ac.uk

Accepted 9 February 2005

\section{REFERENCES}

1 Bishop N, Fewtrell M. Metabolic bone disease of prematurity. In: Glorieux FH, Juppner HA, Pettifor JM, eds. Paediatric bone biology and disease. London: Academic Press, 2003.

2 Nemet D, Dolfin T, Wolach B, et al. Quantitative ultrasound measurements of bone speed of sound in premature infants. Eur J Pediatr 2001;160:736-40.

3 Rubinacci A, Moro GE, Noehm G, et al. Quantitative ultrasound for the assessment of osteopenia in preterm infants. Eur J Endocrinol 2003; 149:307-15.

4 Littner Y, Mandel D, Mimouni FB, et al. Bone ultrasound velocity curves of newly born term and preterm infants. J Pediatr Endocrinol Metab 2003; 16:43-7.

5 Gluer CC, Blake G, Lu Y, et al. Accurate assessment of precision errors: how to measure the reproducibility of bone densitometry techniques. Osteoporosis Int 1995:5:262-70.

6 Yiallourides M, Savoia M, May J, et al. Tibial speed of sound in term and preterm infants. Biol Neonate 2004;85:225-8. 